\title{
KESANGGUPAN KINERJA MENGGUNAKAN HARVARD STEP TEST
}

\author{
Gempur Santoso $^{1)}$ dan Suning ${ }^{2)}$ \\ ${ }^{1}$ Fakultas Teknologi Industri Universitas PGRI Adi Buana Surabaya \\ ${ }^{2}$ Perencanaan Wilayah dan Kota Fakultas Teknik Sipil dan Perencanaan Universitas PGRI Adi Buana \\ Surabaya \\ Email: ' gempursantoso@unipasby.ac.id, suning@unipasby.ac.id ${ }^{2}$
}

\begin{abstract}
Abstrak
Kinerja sesuatu yang penting dalam kesanggupan melaksanakan tugas. Mahasiswa yang termasuk jenis pekerja ringan, perlu juga memiliki indeks kesanggupan yang baik maupun sedang. Penelitan ini menggunakan metode percobaan terhadap 23 orang mahasiswa. Semua responden berjenis kelamin laki-laki. Percobaan dilakukan di Laboraturium Ergonomi Teknik Industri Universitas PGRI Adi Buana Surabaya. Hasil penelitian menunjukkan kinerja ada yang memiliki kesanggupan kurang dengan jumlah 11 orang mahasiswa (47,83\%), memiliki kesanggupan sedang 8 orang (34,78\% ), dan memiliki kesanggupan baik ada 4 Orang (34,78\%). Oleh karenanya agar kinerja bagus, maka harus pemanasan sebelum tes, makan yang cukup, tidak lelah, jantung beerja baik atau VO2max terpernuhi.
\end{abstract}

Kata Kunci: Kinerja, Ideks Kesanggupan, Havard Test, Ergonomis.

\begin{abstract}
Performance is important in the ability to carry out tasks. Students who are categorized as light workers, also need to have a good ability index or moderate. This research used an experimental method of 23 students. All respondents were male. The experiment was conducted at the Industrial Engineering Ergonomics Laboratory, PGRI Adi Buana University, Surabaya. The results of the study showed that there were those who had less ability with 11 students (47.83\%), who had medium abilities of 8 people (34.78\%), and had good abilities there were 40 people (34.78\%). Therefore, for good performance, it must warm up before the test, eat enough, not get tired, the heart is working well or VO2max is fulfilled.
\end{abstract}

Keywords: Performance, Capability Index, Havard Test, Ergonomic.

\section{PENDAHULUAN}

Kebugaran jasmani bagian dari aktifitas manusia yang sangat penting dalam menjaga keseimbangan pola hidup manusia. Hal ini disampaikan oleh Wijayanti, dkk (2014) bahwa kekuatan fisik pada tubuh seseorang kaitannya dengan kebugaran jasmani akan efektif dan efisien dalam waktu yang lama jika aktivitas fisik dilakukan secara teratur dan dan terus menerus tanpa mengalami kelelahan yang berarti. Namun nilai kebugaran jasmani setiap orang berbeda-beda dengan aktifitas yang dilakukannya.

Menjaga tingkat kebugaran jasmani pada tubuh memiliki beberapa manfaat penting yang didapat, yaitu meningkatkan 
kekuatan fisik pada tubuh untuk melakukan aktivitas sehari-hari, mengurangi resiko kelelahan fisik dalam beraktivitas, mendapat psikolog yang baik sehingga dapat mengurangi stress dan terhindar dari penyakit yang dapat menurunkan kinerja tubuh. Seseorang akan mengalami kinerja tubuh yang rendah apabila tidak menjaga tingkat kebugaran jasmani dalam tubuhnya. Prabowo (2013) menjelaskan bahwa tingkat kebugaran jasmani secara langsung mempengaruhi penurunan kinerja dan produktivitas tubuh. Dampak ini dalam waktu yang cukup lama menyebabkan timbulnya penyakit degenerative dan penyakit kardiovaskuler

.Kebugaran jasmani dapat diketahui melalui berbagai cara. Gerakan anggota tubuh dan badan pada takaran tertentu dan dilakukan secara rutin/teratur akan menimbulkan kebugaran jasmani yang tinggi. Namun jika dosis latihan yang dilakukan berada dibawah takaran yang telah ditentukan tidak akan menimbulkan kebugaran jasmani yang dikehendaki. Dan sebaliknya gerakan latihan yang melebihi takaran yang telah ditentukan akan merusak tubuh. Pada umumnya untuk mengukur kebugaran jasmani dapat dilakukan melalui tes kebugaran (Harvard Step Test).

Percobaan ini diawali dengan mahasiswa mempelajari pengaruh aktivitas terhadap kinerja jantung dan perubahan fisiologis dengan melaksanakan tes kebugaran (Harvard Step Test) untuk menentukan kesanggupan kinerja fisik pada mahasiswa dengan mengukur denyut nadi dengan tingkat kebugaran jasmani.

Tujuan dari percobaan tes kebugaran (Harvard Step Test) antara lain untuk menentukan kesanggupan/kekuatan fisik mahasiswa untuk melakukan suatu kerja (menentukan kapasitas kerja). Selain itu, mengetahui hubungan antara tingkat kebugaran jasmani dengan frekuensi denyut nadi untuk mengukur indeks kesanggupan badan.

\section{METODOLOGI PENELITIAN}

\section{Nama Percobaan}

Percobaan Harvard (Harvard Step Test)/Naik Turun Bangku dengan metode cepat, dengan jumlah 23 mahasiswa laki-laki usia rata-rata 19-21 tahun dari Teknik Industri 2018 C, di ruang laboratorium Ergonomi Teknik Inndustri, Universitas PGRI Adi Buana Surabaya.

\section{Alat dan Bahan}
a. Bangku Harvard modifikasi khusus laki-laki $(\mathrm{t}=47 \mathrm{~cm})$
b. Pengukur waktu $($ Arloji $/$ Stopwatch $)=2$ alat
c. Metronome ketukan 120x/menit

\section{Prosedur Kerja}

a. Sebelum percobaan dimulai aturlah metronome dengan irama 120 kali per menit yaitu sesuai dengan kecepatan naik turun bangku yang akan dilakukan.

b. Ukur kecepatan denyut nadi setelah percobaan naik turun bangku (keadan istirahat), dihitung selama 0,5 menit (posisi duduk).

c. Lakukan pemanasan sebelum percobaan test dimulai.

d. Pada saat aba-aba "Mulai" diberikan, orang yang di uji agar menempatkan salah satu kakinya di atas bangku tepat pada detikan metronome yang pertama kemudian stopwatch 1 ditekan. Pada detikan metronome yang kedua, orang 
tersebut harus berada/naik diatas bangku, dan pada detikan metronome yang ketiga satu kaki diturunkan (kaki yang pertama naik bangku) dan disusul dengan kaki yang satunya pada detikkan yang keempat.

e. Kerja dilakukan sesanggup mungkin tetapi tidak lebih dari 5 menit.

f. Posisi tubuh selama naik turun bangku harus tetap lurus (sikap tegak) dan tidak boleh membungkuk.

g. Bilamana sikap atau irama tetap salah selama 10-15 detik walaupun sudah berkali-kali diberi peringatan, maka test harus dihentikan dan lamanya naik turun bangku kemudian dicatat.

h. Pada saat test dihentikan orang yang bersangkutan secepatnya disuruh duduk dan kedua stopwatch ditekan. Penekanan stopwatch yang pertama untuk menunjukkan lamanya naik turun bangku dan penekanan stopwatch yang kedua untuk memulai menghitung periode pemulihan denyut nadi setelah test selesai dilakukan.

i. Kemudian lakukan pencatatan denyut nadi selama 0,5 menit untuk menghitung indeks kesanggupan badan (IKB).

Rumus Indeks Kesanggupan Badan (Cara Cepat) :

$I K B=\frac{\text { Lamanya naik tutun bangkudalam detik } \times 100}{5,5 \times \text { denyut nadi selama } 30 \text { detik }}$
Cara Penilaiannya adalah sebagai berikut :

- Kurang dari $50=$ Kesanggupan Kurang

- $50-80=$ Kesanggupan Sedang

- Diatas 80 Kesanggupan Baik 


\section{ANALISIS DAN PEMBAHASAN}

\section{a. Hasil Percobaan}

Tabel 1. Penilaian Harvard

\begin{tabular}{|c|c|c|c|c|c|}
\hline No & Nama & $\begin{array}{c}\text { Lamanya } \\
\text { (dalam } \\
\text { detik) }\end{array}$ & $\begin{array}{c}\text { Nadi } \\
(0.5 \\
\text { menit })\end{array}$ & IKB & Keterangan \\
\hline 1 & Firdaus Tobby Meidityan & $01^{\prime} 54^{\prime \prime}$ & 57 & 36,4 & Kesanggupan Kurang \\
\hline 2 & M. Andrias & $03 ' 25^{\prime \prime}$ & 60 & 62,1 & Kesanggupan Sedang \\
\hline 3 & Rizal Arif Pribadi & $0 ’ 55^{\prime \prime}$ & 61 & 16,4 & Kesanggupan Kurang \\
\hline 4 & Muhammad Andi A. & 04'07'” & 65 & 69 & Kesanggupan Sedang \\
\hline 5 & Gerhana Aditya Putra S. & $02 ' 54 "$ & 63 & 50,2 & Kesanggupan Sedang \\
\hline 6 & Achmad Samsudin & 03'22”' & 64 & 57,4 & Kesanggupan Sedang \\
\hline 7 & Rakhmadan Afif Irawan & 02'17'” & 59 & 42,2 & Kesanggupan Kurang \\
\hline 8 & Khisbullah Huda & $01^{\prime} 21^{\prime \prime}$ & 64 & 23 & Kesanggupan Kurang \\
\hline 9 & Fami Janisa Fahrudin & $05^{\prime} 00^{\prime \prime}$ & 66 & 82,6 & Kesanggupan Baik \\
\hline 10 & Muhammad Aditya & $03 ' 11 "$ & 58 & 60 & Kesanggupan Sedang \\
\hline 11 & Moch. Hendrawan H & $01^{\prime} 37^{\prime \prime}$ & 56 & 31,5 & Kesanggupan Kurang \\
\hline 12 & Wahyu Hidayat & $01 ' 12 ”$ & 53 & 24,7 & Kesanggupam Kurang \\
\hline 13 & Ahmad Nuril Fahmi & 01'33'” & 54 & 31,3 & Kesanggupan Kurang \\
\hline 14 & Wahyu Ardiansyah & $01 ' 52 ”$ & 57 & 35,7 & Kesanggupan Kurang \\
\hline 15 & Mulik Dhany Ilmanafi & 0’48”' & 53 & 21,9 & Kesanggupan Kurang \\
\hline 16 & Muhammad Annas M. & 03’01” & 58 & 56,7 & Kesanggupan Sedang \\
\hline 17 & Thomas Yudianto & $01 ' 41 "$ & 56 & 32,8 & Kesanggupan Kurang \\
\hline 18 & Haidar Muhammad Aji & $01^{\prime} 46^{\prime \prime}$ & 54 & 35,7 & Kesanggupan Kurang \\
\hline 19 & Yuski Ade Ilham & 03'13”' & 59 & 59,5 & Kesanggupan Sedang \\
\hline 20 & Muhammad Kevin F.A.R. & 03'36"' & 60 & 65,5 & Kesanggupan Sedang \\
\hline 21 & Nur Musthofa & $05^{\prime} 00^{\prime \prime}$ & 63 & 86,6 & Kesanggupan Baik \\
\hline 22 & M. Ricky Fareza Putra & $05^{\prime} 00^{\prime \prime}$ & 65 & 83,9 & Kesanggupan Baik \\
\hline 23 & Muhammad Sirojul M. & $05^{\prime} 00^{\prime \prime}$ & 64 & 85,2 & Kesanggupan Baik \\
\hline
\end{tabular}

Sumber : Data Praktek Mahasiswa Teknik Industri 2018 C (Desember 2019)

\section{b. Analisis Hasil Percobaan}

Rumus Presentase :

$$
\frac{\text { Hasil Test }}{\text { Jumlah Frekuensi }} \times 100=\%
$$

Tabel 2. Hasil Presentase

\begin{tabular}{c|c|c}
\hline Hasil Test & Frekuensi & Presentase \\
\hline $\begin{array}{c}\text { Kesanggupan } \\
\text { Kurang }\end{array}$ & 11 & $47,83 \%$ \\
\hline Kesanggupan & 8 & $34,78 \%$ \\
\hline
\end{tabular}

\begin{tabular}{c|c|c}
\hline Sedang & & \\
\hline $\begin{array}{c}\text { Kesanggupan } \\
\text { Baik }\end{array}$ & 4 & $\mathbf{1 7 , 3 9 \%}$ \\
\hline
\end{tabular}

Dilihat dari data percobaan tes (tabel 2.), hasil dengan kategori kesanggupan kurang lebih banyak dialami oleh mahasiswa dengan jumlah 11 mahasiswa dengan lamanya aktivitas naik turun bangku berkisaran dari 48 detik hingga 2 menit lebih 17 detik, dengan denyut nadi berkisaran 53-64 
denyutan. Faktor penyebab terjadinya kesanggupan kurang bisa terjadinya karena kondisi tubuh dalam keadaan tidak maksimal (kurangnya asupan gizi atau nutrisi pada tubuh), kurangnya waktu istirahat, dan kuarngnya berolahraga secara terastur. Selain itu, posisi dalam percobaab test tidak sesuai dengan prosedur, atau kuranggnya serius dalam pemanasan sebelum percobaan test. Untuk Kesanggupan Sedang dan Baik diprediksi dapat memenuhi target kesanggupan kinerja seseorang dalam beraktivitas secara terus menerus dalam waktu lama namun dengan pola hidup yang sehat, olahraga teratur dan seimbang.

Hasil percobaan yang didapat, belum tentu menunjukkan mahasiswa yang dalam percobaannya masuk kategori kurang dianggap tidak memenuhi kesanggupan kinerja, hal ini dipengaruhi oleh faktor lain seperti pemberian beban kerja yang berlebih dibandingkan biasanya dan tidak diawali dengan melakukan pemanasan terlebih dahulu. Selain itu frekuensi naik turun harvard kurang maksimum, atau bisa jadi penggunaan rumus pada uji laboratorium masih dominan untuk uji standart orang luar negeri dengan beban kapasitas kerja lebih, gizi makanan dan pola hidup seimbang jika dibandingkan dengan orang Indonesia.

Harvard step test merupakan metode yang digunakan untuk mengukur indeks kebugaran jasmani melalui naik turun bangku setinggi $47 \mathrm{~cm}$ bagi laki-laki dan $40 \mathrm{~cm}$ bagi perempuan selama 5 menit sesuai dengan irama metronome dengan mengkategorikan tingkat kebugaran jasmani menjadi kesanggupan kurang, sedang, dan baik (Gempur, S. 2018 : 13-19). Dalam mengkategorikan tingkat kebugaran jasmani tergantung dari durasi dan intensitas saat melakukan aktifitas fisik. Selain itu, Harvard step test menjadi salah satu jenis tes stress jantung untuk mendeteksi dan atau mendiagnosa kelainan kardivaskuler. Semakin cepat jantung kembali normal maka semakin bugar tubuhnya.

Sugianto \& Nurhayati mendeskripsikan suatu tingkat kebugaran jasmani yang dimiliki seseorang baik jika terdapat daya tahan kardiovaskuler yang baik. Daya tahan kardiovaskuler ini dapat berfungsi secara optimal pada saat melakukan aktivitas sehari-hari dalam waktu yang cukup lama tanpa mengalami kelelahan. Kondisi ini terjadi karena ada peningkatan kekuatan otot kardiovaskuler, dimana otot tersebut mampu meningkatkan kesanggupan jantung untuk memompa darah lebih banyak dan lebih lancar ke seluruh tubuh.

Indikator untuk mengetahui daya tahan kardiovaskuler adalah dengan pengukuran frekuensi denyut nadi. Denyut nadi adalah suatu gelombang yang teraba pada arteri bila darah dipompa keluar dari jantung. Denyut nadi dapat dirasakan akibat getaran denyut darah didalam pembuluh darah arteri akibat kontraksi ventrikel kiri jantung. Pengecekan denyut nadi paling sering dilakukan dengan meraba pada bagian atas pergelangan tangan pada sisi ibu jari. Menurut Hermawan, Subiyono \& Rahayu, (2012) orang dewasa yang sehat, saat sedang istirahat memiliki denyut jantung yang normal yaitu 60-100 denyut per menit sedangkan pada orang yang terlatih rutin melakukan olahraga fisik denyut nadi normal dapat mencapai 50-60 denyut kali per menit. Apabila dalam keadaan istirahat, frekuensi denyut jantung lebih rendah maka menunjukkan fungsi jantung lebih efisien dan kebugaran kardiovaskular lebih baik.

Frekuensi denyut nadi pada seseorang dapat berubah sesuai dengan aktivitas fisik yang dilakukan. Terdapat beberapa faktor yang dapat mempengaruhi frekuensi denyut nadi, yaitu jenis kelamin, latihan fisik, usia, riwayat merokok, dan indeks massa tubuh. 
Pada individu yang bugar, detak jantung atau denyut nadi lebih sedikit jumlahnya bila dibandingkang dengan individu yang memiliki tingkat kebugaran jasmani rendah.

Secara empiris manusia memiliki kinerja yang harus direncanakan, dirancang dan didesain sebaik mungkin untuk menghasilkan output kinerja secara optimal. Hal inilah yang kemudian secara fisiologi manusia mengalami kelelahan otot selama bekerja jika tidak dikendalikan dan dievaluasi sistem kerja yang dilakukan. Ergonomi secara teoritik maupun praktik dapat dikatakan sebagai media preventif untuk dapat meminimalkan gejala kelelahan dan resiko terhadap rusaknya tulang dan otot saat bekerja yang dilakukan secara berulangulang. Oleh karenanya dibutuhkan strategi yang baik untuk dapat mengatur kemampuan diri dalam system kerja manusia, dengan keterbatasan dan kapasitas tempat kerja yang disesuaian dengan kepasitas tubuh normal manusia.

Dalam sistem kerja manusia membutuhkan VO2max untuk metabolisme sel dan produksi energi. Waktu yang dibutuhkan biasanya 1 menit dengan jumlah oksigen yang digunakan oleh otot selama interval tertentu. Plowman \& Smith (2011) juga menjelaskan bahwa VO2max dengan volume oksigen maksimal yang di konsumsi oleh tubuh manusia diperoleh dari kegitan aerobik sambil menghitup udara saat latihan berat maupun sederhana yang dihasilkan dari energi (ATP). Energi (ATP) dalam produksinya memiliki suatu proses yang secara sistemik mampu membawa oksigen dari udara, kemudian menganggkut oksigen dan sel yang berasal dari sistem kardiovaskuler yang secara berurutan berasal dari sistem pernapasan. Oleh karena itu kebugaran seseorang dapat digambarkan dari VO2max yang secara rutin juga dapat menggambarkan adanya kardiorespiratori seseorang. Hal ini juga dapat dikatakan besarnya VO2max yang dibutuhkan dapat mempengaruhi a) fungsi jantung, paru dan pembuluh darah, b) proses penyampaian oksigen ke jaringan oleh eritrosit yang melibatkan fungsi jantung untuk memompa darah, c) volume darah, d) jumlah sel darah merah dalam pengalihan darah dari jaringan yang kemudian ditranspor ke otot-otot yang sedang bekerja (Sharkey, 2011).

Faktor-faktor yang mempengaruhi nilai VO2max pada setiap individu, dapat ditinjau dari, 1) Genetik, pada kekuatan otot dan daya tahan otot; 2) Usia, mempengaruhi daya tahan kardiovaskular; 3) Jenis Kelamin, perbedaan hormonal menyebabkan wanita memiliki hemogoblin lebih rendah dan lemak tubuh lebih besar, serta massa otot yang lebih kecil. Semua berbanding terbalik dengan yang dimiliki oleh laki-laki; 4) Keadaan Latihan/Aktivitas Fisik, ketahanan kardiorespirasi akan dimiliki seseorang jika seseorang tersebut memiliki otot lebih kuat, lebih lentur dan kondisi ini terjadi karena terlatih. Kondisi ini pada gilirannya akan meningkatkan daya tahan kardiovaskular yang mana terdapat penurunan denyut nadi, pernafasan membaik, resiko penyakit jantung dan hipertensi mengalami penurunan; 5) Komposisi Tubuh, kegemukan cenderung mengurangi VO2max. Lebih diperhitungkan melalui IMT (Indeks Masa Tubuh), hasil dari berat badan (kilogram) dibagi kuadrat dari tinggi badan (meter). Hasil penelitian Sharkey (2011) tentang VO2max disimpulkan bahwa VO2max merupakan jumlah oksigen yang dikonsumsi manusia secara optimal dan dapat dijadikan indikator terbaik untuk ketahanan seseorang saat melakukan aerobic, selama terdapat keseimbangan akan kebutuhan tubuh antara aktifitas, gizi seimbang dan olah pernapasan. 


\section{KESIMPULAN}

Kinerja yang dimiliki mahasiswa lakilaki Teknik Industri 2018 C dominan menuju kesanggupan kurang dengan jumlah 11 mahasiswa dengan presentase $47,83 \%$ dari jumlah keseluruhan 23 mahasiswa. Didapatnya kesanggupan yang kurang, dikarenakan ada indikator beban kerja yang melebihi kapasitas dari biasanya serta gizi dan pola hidup yang kurang seimbang. Kinerja yang dimiliki mahasiswa laki-laki Teknik Industri $2018 \mathrm{C}$ hanya memiliki kesanggupan sedang sebanyak 8 orang $(34,78 \%$ ) dan kesanggupan baik sebanyak 4 oang $(34,78 \%)$. Kinerja dengan kesanggupan sedang dan baik ini yang siap secara fisik meliputi tidak lelah, VO2-max, dan gizi tercukupi.

\section{SARAN}

Sebaiknya mahasiswa yang akan melakukan percobaan Tes Harvard dalam keadaan baik dan memenuhi prosedur kerja tes agar hasil yang didapatkan maksimal. Hal itu harus pemanasan, makan yang cukup, tidak lelah, jantung baik atau VO2max terpernuhi. Selain itu, alat yang digunakan dalam laboratorium sebaiknya di cek terlebih dahulu atau ditambah untuk kelancaran praktikum

\section{REFERENSI}

Hermawan. L , Subiyono \& Rahayu. (2012). Pengaruh Pemberian Asupan Cairan (Air) Terhadap Profil Denyut Jantung Pada Aktivitas Aerobik, Journal of Sport Sciences and Fitness. 1 (2).

Plowman, S. A., \& Smith, D. L. (2011). Exercise Physiology For Heath, Fitness, And Performance. Philadhelphia : Lippincott William \& Wilkins.
Prabowo, S. B. (2013). Tingkat kebugaran jasmani anggota klub jantung sehat mugas kota semarang. Skripsi tidak diterbitkan. Semarang : UNS (http://lib.unnes.ac.id/19396/1/610140 9022.pdf diakses pada tanggal 05 Mei 2020).

Santoso, G. (2018). Panduan Praktek Ergonomi. Surabaya : unipress.

Sharkey, B.J. (2011). Kebugaran dan Kesehatan. Edisi ke 2. Jakarta : Raja Grafindo Persada.

Sugiyanto, B \& Nurhayati, F. (2014). Hubungan Antara Daya Tahan Jantung Dan Paru-Paru Dengan Prestasi Akademik Pada Siswa Kelas Viii Smp Negeri 1 Tarik Tahun Ajaran 20122013. Jurnal Pendidikan Olahraga dan Kesehatan. 2 (1).

Wijayanti, D., Yuwono, C \& Pujianto, A. (2014), Survei Tingkat Kebugaran Jasmani Pada Siswa-Siswi Tuna Grahita SMP Luar Biasa Negeri Kota Salatiga. Journal of Physical Education, Sport, Health and Recreation.1 (2). 
WAHANA

Volume 72, Nomor 1, 1 Juni 2020
e-ISSN 2654-4954, p-ISSN 0853-4403 